\title{
Countermeasure Analysis on Internet Logistics
}

\author{
Shao Ying TENG ${ }^{1, *}$, Xiao Jun $\mathrm{LI}^{1}$,Zhi ZHAO ${ }^{1}$,Peng Lei QIN ${ }^{1}$,Ya Ya LU ${ }^{1}$ \\ ${ }^{1}$ Shandong Jiaotong University, Ji'nan, Shandong 250300, China
}

\begin{abstract}
The rapid development of Internet technology has caused a series of industrial revolution, which has provided strong impetus for economic development. The Internet + concept puts forward the deep integration between the Internet and traditional industries, which points out the direction for the development of various industries. For the logistics industry, "Internet + " provides a new way of transformation, and intelligent logistics, smart logistics and green logistics bring new business value to the logistics industry. This paper analyzes the current situation of the logistics industry in the context of Internet + , finds out the existing problems, and proposes corresponding solutions to provide the impetus for further development of the logistics industry.
\end{abstract}

\section{Background}

In other words, "the Internet" is "the traditional industries of the Internet," but this is not a simple combination of the two, but the use of information and communications technology and Internet platforms, so that the Internet and traditional industries are deeply integrated. Create a new development ecology. [1] the "Internet" of the logistics industry is not a mere addition of concepts, but a fusion of the two, and the Internet logistics industry, It is based on the application of Internet of things and Internet technology to realize the globalization, internationalization, information and intelligence of logistics, thus improving the level of productivity and market competitiveness. Optimize the allocation of social resources and promote the formation of a new social form of logistics development. Compared with traditional logistics, the "Internet" logistics can optimize logistics efficiency and become closer through the latest network technology. Connecting the integrated development model between logistics enterprises smoothly, reducing the waste of resources, achieving the goal of improving the efficiency of logistics management. Customers and suppliers are no longer isolated individuals. The online information platform formed by the "Internet" enables the third party logistics enterprises to realize the integration of resources, making vehicles and personnel, Physical and non-entity information implementation data, such as inventory, business processes, etc. Transformation and sharing ${ }^{[2]}$

At the third session of the 12 National people's Congress on the morning of March $5^{\text {th }} 2015$, Premier Li Keqiang put forward the "Internet" action plan for the first time in the government work report, and the "Internet" was included in the government work report. In the government work report, Li Keqiang put forward the "formulation of the" Internet "action plan. Promote the integration of mobile Internet, cloud computing, big

* Corresponding author:Email: 1300142749@qq.com data and Internet of things with modern manufacturing, and promote the healthy development of e-commerce, industrial Internet and Internet of Finance. It is proved that Internet logistics has become a major trend in the development of logistics industry in China in the future. Home will be the Internet logistics into the key planning, Internet logistics will take advantage of the popular entrepreneurship, innovation, rapid development. This is both an advantage and a challenge for the logistics industry. ${ }^{[3]}$

\section{Industry Analysis}

\subsection{Low Efficiency of Logistics System and High Cost of Logistics Transportation}

According to the data of the National Bureau of Statistics in the first three quarters of 2017, the total amount of social logistics was 184.8 trillion, an increase of 6.9 percent over the same period last year. The total revenue of the logistics industry was 6.3 trillion yuan, up 13.3 percent from the same period last year. As shown in Figure 1 and 2 try, when the total amount of social logistics and transportation costs are so high,the production volume of transportation per 10,000 yuan gross product is 4,853 tons, while in the United States and Japan, the production volume of transportation per 10,000 yuan gross product is 870 tons and 700 tons, respectively. The gap is very big, and the operation efficiency of logistics system in our country is low, and the continuity of the link between each link is low. There is also unreasonable organization in the freight transportation link According to statistics, the logistics organization of road freight transport, the empty driving rate has remained at 50 for many years; railway, aviation, navigation, there are also a variety of problems. 


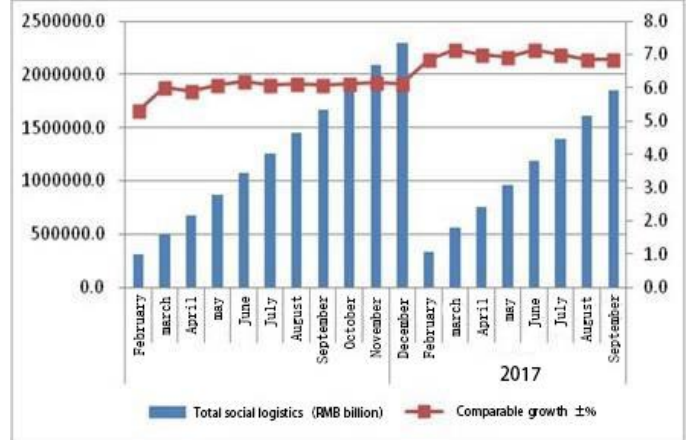

Figure1.The total social logistics growth trend

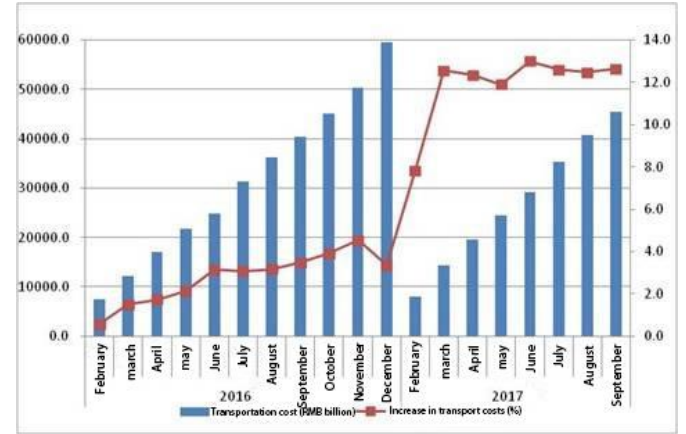

Figure2.Growth trend of transportation cost

\subsection{Low Degree of Standardization in Logistics Enterprises}

Although the state and related units have stipulated various indexes in the logistics process, there are still many problems. For example, there are two standards for domestic pallets and a variety of standards for containers. The standards for road and railway containers are also not uniform. There are different standards for transport equipment, handling equipment and storage equipment in different companies or regions. This is in transportation, storage, handling and handling. Packaging and circulation of processing and other aspects of the formation of different standards,logistics transportation also has a lot of inconvenience.

\subsection{Insufficient Construction of Logistics Infrastructure}

In 21 th century, with the rapid development of traffic construction, although China made great achievements in railway and bridge construction, it was compared with other Asian countries, such as Europe, America and even India. There is still a certain gap. According to the land area and the density of transportation network, our country is only $1,344.48 \mathrm{~km} / \mathrm{km} 2$, while the US is $6,869.3 \mathrm{~km} / 10000 \mathrm{~km} 2$, and Germany is $14680.4 \mathrm{~km} /$ $10,000 \mathrm{~km} 2$. India is $5403.9 \mathrm{~km} / 10000 \mathrm{~km} 2$ [1]. Transportation network has great influence on logistics and transportation. From this point of view alone, the infrastructure construction of our country not only lags behind. There is also a significant gap between Dharma and developing countries such as India. In terms of building storage facilities, although the state has made great efforts to help and formulate relevant policies, it still has space efficiency and refrigeration. There are still many problems in the construction of warehouses such as air conditioners. As far as we know, among the warehouses owned by third-party logistics enterprises, bungalow warehouses account for $70 \% \%$, and there are cold storage and storage. Air conditioning and other functions of modern logistics warehouse accounts for a small proportion.

\subsection{Low Degree of Automation in Logistics Enterprises}

Since 2015, the state has vigorously developed automated logistics. According to the China Logistics Association, the penetration rate of warehousing automation in developed countries reached about $80 \%$ in 2017. In China, it is only about 20. And although domestic enterprises are vigorously developing automated warehousing and sorting, most small and medium-sized enterprises are still stagnant in automation development and have a lot of problems. The degree of automation also changes with the change of logistics price index (Figure 3).

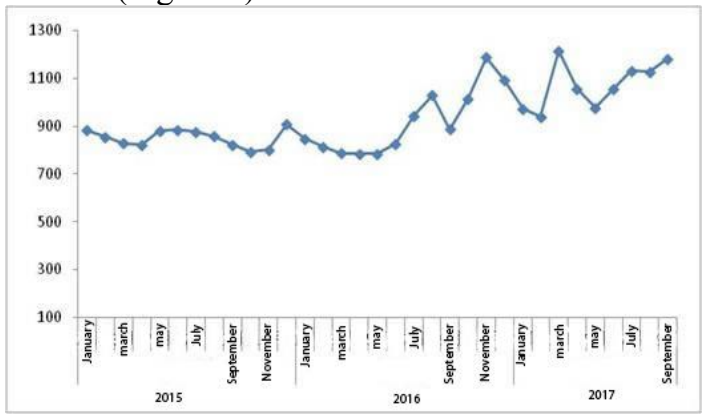

Figure3. Change trend of logistics freight price index

\subsection{Logistics Talent Shortage}

With the rapid development of logistics service industry in China, the demand for logistics talents is increasing day by day in the market, which requires a large amount of investment of logistics talents. According to a survey in 2017, due to the emergence of "people-oriented" social concept, Talent has become the first element for enterprises to seek survival and development. Our country now has a sharp shortage of middle and advanced logistics personnel, especially proficient in traditional transportation, warehousing and the effective use of modern information means. Familiar with logistics operators and experts. However, due to the recent emergence of logistics enterprises to vigorously train staff, as well as corporate system problems; and logistics professionals, most of the current high school students are not familiar with the situation of the enterprise, There are many problems in the formulation of enterprise goals and strategies, as well as in the decision of most programs, so high quality logistics personnel are very short.

\subsection{Low Degree of Information in Logistics Enterprises}


According to the information received, logistics enterprises plan, organize, lead, control and prevent all kinds of accidents from taking orders for transportation, warehousing, sorting and packaging, etc. However, the overall logistics planning capability of logistics enterprises in China is relatively low. The overall level of information application is relatively low, only a small number of enterprises have information systems that are limited to financial management, human resources management, customer relationship management, establishment of intranets, websites and web pages of enterprises, etc. Most businesses simply use computers as an operating tool to process simple documents and forms.

\subsection{High Vehicle Vacancy Rate and Mismatch}

There are a lot of problems in the logistics and transportation industry of our country, such as a large number of empty driving and unreasonable route, the empty driving rate of automobile is as high as $40 \%$, and the mismatch of vehicle and cargo causes a lot of waste of resources. According to the recent survey data, The number of truck drivers in China has reached more than 50 million, carrying more than $75 \%$ goods in the country. Although there has been the emergence of software such as "Lala of goods", the transactions are still based on the introduction of family, fellow countrymen, and friends in the circle. Even transactions with logistics companies are based on acquaintance patterns. These phenomena have exacerbated the conflict that goods cannot be found and cars cannot be found. Drivers find the right goods on their way back It is very difficult, in order to avoid the return of empty driving, truck owners often through the intermediary to obtain source information, further increase costs, diluted profits.

\section{Countermeasure Analysis}

\subsection{Strengthening the Leadership Function of the Government and Improving the Function of the Laws and Regulations of Logistics}

With the rapid development of the Internet today, it is very necessary to actively establish a comprehensive coordination center centered on the unified planning of the government, and to plan the development of the logistics industry as a whole. We must take advantage of the beneficial side of the Internet for development. Perfecting the laws and regulations of the logistics industry and breaking down the barriers between different enterprises can not only maximize the utilization of resources among different enterprises, but also enable the enterprises to give full play to their respective duties and supervise each other. The role of standards in the industry.

\subsection{Strengthen the Alliance of Small and Medium-Sized Logistics Enterprises, Perfect the Standardization and Automation of Enterprises}

Small and medium-sized logistics enterprises are one of the biggest problems in the development of logistics process standardization and automation. What is necessary to develop Internet logistics is the standardization and automation of logistics process. It is more difficult to standardize and automate logistics. To strengthen the alliance between small and medium-sized logistics enterprises can improve the talents, funds, land area and other important obstacles among enterprises, which can make the resources of each enterprise to be maximized. For large enterprises, the problem of capital and industrial area is not a very important obstacle, which requires leaders to be conscious To gradually standardize and automate their logistics processes, such as the standardization of facilities and equipment in storage, handling and handling, and the automation of facilities and equipment in sorting and packaging, etc. Can effectively solve the small and medium-sized logistics enterprises in the development of Internet logistics process.

\subsection{Improve the Infrastructure Construction in the Process of Logistics and Strengthen the Utilization Ratio of Space}

According to the development trend of modern Internet plus logistics infrastructure, logistics process improvement is imperative. Perfect infrastructure can reduce space and time effective logistics process of each logistics enterprise. For example, the automation program of the enterprise will inevitably require to improve the infrastructure support, if infrastructure is still according to the original standard transport, packaging and other work, it is bound to the existence of middle Carlton, not only the high operation of logistics process, it is a waste of new resources, waste of the Internet. And every enterprise can use the Internet time allocation, to achieve win-win cooperation. In per capita land resources Nowadays, it is necessary to use the Internet to enhance the utilization of space in the process of logistics. The Internet can strengthen the cooperation among enterprises on a large scale and make the most effective use of space.

\subsection{Actively Train Modern Logistics Talents}

As a new concept of Internet logistics, the talents in the industry are scarce, and most of the talents in the enterprises are still using old knowledge and introducing new talents. Giving full play to the uniqueness of the new type of talents and making the new and old knowledge collide with the strongest force are the most important problems facing the enterprises today. The preservation of internal information in cooperation is also an aspect of identifying new talents.

\subsection{Strengthening the Information Construction of Logistics}

In the development of the Internet, the most important thing is the use of Internet information. The Internet is a 
shared platform. The information published and searched by each enterprise on the Internet will play an important role in the development of the enterprise. With the construction of logistics information, each logistics enterprise can not only see the information of other enterprises on the Internet. More can let their own information needs the enterprise and the talented person to see, each enterprise realizes the information sharing, the cooperation altogether wins the good desire.

\subsection{Optimize the Transportation Route Reasonably and Improve the Transportation Efficiency}

Using the Internet to understand information and rationally plan transportation routes can not only save time, but also save manpower, material resources, capital and other resources, reduce duplication of routes, and improve transportation efficiency. Optimize the transportation route, can make the enterprise internal resources reasonable use, efficient operation.

\subsection{Strengthening the Construction of Network Platform}

The network platform construction is the most important construction in the development of Internet, perfect network platform can not only be used as an advertising to promote their own business, more can let more enterprises and talents to see themselves in the Internet, increase the opportunities for cooperation. For a very strong momentum of development of enterprises in the Internet tide, perfect the network platform sharing platform can win more color and opportunities and better for themselves. The network platform is the foundation of a new era of logistics enterprise at the development of the network platform construction more perfect is the priority among priorities of each logistics enterprise.

\section{Conclusion}

With the continuous development of the "Internet" logistics model, the logistics industry will welcome a series of opportunities and challenges. Logistics industry should seize the opportunity to deal with the new development opportunities and problems brought by this model to the logistics industry with the correct mentality. This paper analyzes its own problems, thinks deeply according to the present situation, promotes its own strength, conforms to the trend of development of the times, and actively adapts to the new market demand, so that the industry is in an invincible position in the development trend of the times.

\section{References}

1. Interpretation: what is the "Internet + " in the report of li keqiang? HTTP: / / pa. Caijing. Com. Cn / 20150305/3832729. SHTML, 2015-03-05.

2. Wang xianqing, li zhengkun, liu fangdong, etc.
Internet + logistics [M]. Beijing: people's post and telecommunications press, 2015.

3. Wang qifeng. Research on the value of logistics service in the "Internet plus" environment [J]. Logistics technology, 2016(11).

4. $\mathrm{Xu}$ chunyu. Analysis of logistics problems and solutions in small and medium-sized enterprises in China [J]. China science and technology expo, 2013, (12) : 23-27.

5. Zhang lifeng. Information research on logistics industry $[\mathrm{M}]$. Dongying: petroleum university press, 2013:110-119. 